\title{
Resposta aos comentários
}

\author{
Ronaldo Vainfas \\ Departamento de História, Instituto de Ciências \\ Humanas e Filosofia/Universidade Federal \\ Fluminense
}

O perfume da rosa: vida privada em três tempos

Um dos grandes méritos desta Seção Debates, tal como é concebida, reside em ser ela um espaço de discussão de idéias e perspectivas acerca de um dado objeto. No caso da História, mas não só nele, a crítica, verdadeiro húmus do conhecimento, é sempre benvinda. Crítica na forma de acréscimo de questões insuficientemente abordadas; crítica na forma de correçōes de informações imprecisamente fornecidas; crítica na forma de divergência de pontos de vista, que por vezes assume um tom de frontalidade total. De tudo isso há um pouco nos comentários dos ilustres colegas que se deram ao trabalho de ler o texto-base que escrevi sobre a vida privada como objeto da História. A todos eles devo dizer, antes de tudo, que sou grato. Grato pela tolerância, grato pelo reconhecimento generoso de meu estorço para sintetizar em poucas páginas tema tão delicado. Grato, enfim e sobretudo, pela crítica que já mencionei.

Evidentemente, não me cabe aqui comentar cada um dos textos que dialogaram com o artigo-base - e foram dez -, de sorte que minha opção é a de fazer uma apreciação geral do problema e das questões mais recorrentes no conjunto da crítica. Conto, novamente, com a tolerância dos comentadores para as novas lacunas de meu texto, certo de que entenderão as limitações de espaço inerentes a esta conclusão, além das minhas próprias.

Mas já que toquei em lacunas, vamos a elas como primeiro ponto desta versão final. Não tenho dúvida de que o texto-base resvala para uma certa "inconclusividade", para usar a expressão de José de Souza Martins, talvez o 
mais enfático neste sentido. Mas a mesma impressão tiveram outros debatedores, ainda que em grau menor, como Cardoso Falcon, Laura de Mello e Souza, Fernando Novais, Lana lage, a maioria enfim, de sorte que, seja no conjunto, seja em certos pontos a que voltarei adiante, meu texto deixa inúmeras questões em aberto. Devo dizer que, em boa parte, foi esta uma estratégia que adotei para abordar o tema: uma tentativa de, também através da narrativa, e não apenas por meio da discussão substantiva da matéria, indicar a hesitação dos que propuseram a vida privada como objeto da História, os dilemas teóricos ensejados por tal aventura e as motivaçōes de fundo em que tal debate se inclui. Motivações muito presentes e atuais, como sugere Martins, e que procurei tãosomente mencionar, contrapondo Georges Duby a Richard Sennett: o primeiro a justificar a elaboração de uma história da vida privada como esforço, quiçá nostálgico, para conter a crescente voracidade do público; o segundo a indicar com acuidade a diminuição progressiva, no mundo contemporâneo, do terreno público de significação e ação impessoal.

Sheila de Castro Faria foi algo sensível a este meu procedimento, sugerindo ter sido intencional e estratégica a imprecisão vocabular que reconheci em meu próprio artigo. Celeste Zenha também indicou, com acerto, que meu propósito não foi o de tratar as discussões sobre a vida privada de forma exaustiva, mas sobretudo o de abrir a polêmica, deixar espaços abertos para a incursão dos debatedores. Nem por isso, reconheço, a impressão de "inconclusibilidade" se desfaz e talvez indique minhas próprias hesitações em face das inúmeras questões que o tema enseja. Buscarei, ao longo desta segunda versão, esclarecer, na medida do possível, algumas das imprecisões apontadas.

Outra ordem de lacunas que me foi indicada, neste caso mais específica, diz respeito a autores ou correntes não suficientemente contempladas pelo ensaio e que contribuiriam, se adotadas ou aprofundadas, para o avanço das reflexões. Creio que o rico elenco dos textos críticos com os quais dialogo dá boa mostra de outras possibilidades de abordar ou pensar o tema da História da vida privada, possibilidades diferentes das por mim adoładas. Talvez seja o texto de Falcon o que melhor indique, do ponto de visła da História, e mesmo da Antropologia, um conjunto alternativo de autores, sem dúvida pertinentes, a exemplo de Peter Laslett, Peter Gay, Theodor Zeldin, sem falar dos próprios antropólogos e dos historiadores-demógrafos (ou seria o contrário?) que meu artigo não contempla. No mesmo sentido, e substantivando a crítica, Falcon, Silvia Petersen e outros colegas indicaram o demasiado apego do artigo-base à historiografia francesa como referente de minhas reflexões, "hábito muito nosso, bem brasileiro", escreveu Falcon no seu comentário, ao qual não falta o estilo provocativo que sempre admirei.

Pois bem, seria de todo indesejável, senão impossivel, justificar cada uma das omissões. Algumas delas são mesmo injustificáveis e outras tomariam tempo e espaço de que não disponho. Mas, sem recusar a validez das referidas cobranças (e afinal é disto que se alimenta o presente dossiê), minha opção foi a de restringir a análise aos historiadores que elegeram a vida privada como objeto ou problemática da História. Não é este, por exemplo, o caso de Peter Laslett, o célebre autor de The world we have lost, cujo objeto é a familia, entendida como a unidade doméstica na Inglaterra pré-industrial e pesquisada com base em listas nominativas. Preocupa-the, antes de tudo, demonstrar a precocidade da família 
nuclear na Inglaterra e contestar a generalização de que na Europa pré-industrial predominavam unidades domésticas extensas. Unidade doméstica que, convém embrar, é unidade de coabitação e sobretudo de produção, mais do que cenário de construção de sociabilidades privadas. Não é também a vida privada, definitivamente, o objeto da Demografia Histórica, seja a do grupo de Cambridge, seja a desenvolvida na França por Lovis Henry, Pierre Goubert e outros, desde os anos 1950, senão a dinâmica da população em perspectiva histórica. Os estudos da Demografia Histórica podem contribuir, indiretamente, para a história da vida privada, mas não penso que fazem da construção da privacidade um objeto de investigação.

Algo de semelhante se poderia dizer de Peter Gay, para o século XIX, ou de Jean-Louis Flandrin, para o fim da Idade Média e a Época Moderna, autores preocupados com a construção de uma nova moral, individualizante, auto-censória, especialmente nos domínios da sexualidade. Peter Gay, que me foi solicitado abordar, ou Flandrin, que não me foi, poderiam ser comentados, sem dúvida, assim como a vastíssima plêiade de historiadores que há algumas décadas se dedica à história da sexualidade e do corpo. Afinal, as fronteiras entre privacidade e sexualidade parecem tênues, seja na historiografia, como tentei mostrar na análise da coleção francesa, seja no entendimento comum que muitos têm do termo "vida privada" nos dias que correm. Mas o que seria de um artigo que almejasse discutir as mil e uma fronteiras que a vida privada mantém com diversos domínios da História? Vida privada que, se é conceito, como afirmam Laura de Mello e Souza e Fernando Novais, é conceito polar que se define, antes de tudo, pela oposição ao que seja público. Fiz uma escolha, de fato, e por isso não tive como evitar inúmeras renúncias.

Assim renunciei a expor e discutir diversos historiadores de outras nações, excluindo mesmo o meu preferido, Carlo Ginzburg. Exclui, de igual modo, o diálogo direto com textos antropológicos pertinentes, embora creia que, neste ponto, o artigo de Maria Lúcia Montes fez as devidas articulações mehor do que eu as faria. Tratei mui apressadamente de Henri Lefebvre, conforme apontou Martins, e ainda tive a infelicidade de eleger um texto menor do sociólogo francês, autor de mais de setenta obras. Pelo menos o citei, ao contrário de le Golf ou Duby, mas depois de ler o que José de Souza Martins comentou sobre Lefebvre, melhor seria tê-lo também omitido. A rigor não faria falta, dado que o conceito de cotidiano só interessava a meu artigo de forma ancilar. Tem razão Martins, no entanto, quando aponta o fraco diálogo entre historiadores e sociólogos na atualidade, o que não ocorre, por exemplo, em relação aos antropólogos. A Sociologia, que já foi a "rainha das Ciências Humanas", e contribuiu decisivamente para a "revolução" da historiografia analisada por Peter Burke, anda hoje um tanto ignorada pelos historiadores. Casou-se ou uniu-se a História com a Antropologia, mesmo que com certa antropologia, como diz Ciro Cardoso: a geertziana que, no seu entender, funciona como álibi para o relativismo cultural.

Seja como for, o recorte francês se justifica plenamente por ter sido a França o ambiente em que floresceu, muito antes de ali instituir-se uma historiografia profissional, o interesse pela vida privada como objeto. Foi no século XVIII, século das Luzes e de apologia da razão, que Legrand d'Ausssy 
escreveu seus três volumes intitulados La vie privée des Français, embora se trate sobretudo de obra ligada à história da alimentação. Maria Lúcia Montes me socorre e corrige, neste ponto, acrescentando que o próprio Rousseau das Rêveries du promeneur solitaire poderia ser destacado como filão inaugural desta linhagem francesa a que me refiro, mais do que o próprio Legrand d'Aussy. E foi mesmo na França, como lembra nossa debatedora antropóloga, que mais se estreitaram, desde as primeiras décadas do século, os laços entre a História, a Sociologia de Durkheim e a Antropologia de Mauss, por exemplo. Maria Lúcia Montes menciona L'Année sociologique, e se poderia citar igualmente o célebre artigo de François Simiand, "Méthode historique et science sociale", publicado na Revue de synthèse historique, texto que propôs situar a História no seio das demais ciências sociais, retirando-a do isolamento em que então se achava. Desnecessário lembrar, penso eu, o quanto a história se beneficiou deste diálogo ou a importância renovadora do movimento dos Annales no tocante à interdisciplinaridade.

A História da vida privada é, portanto, em múltiplos aspectos, filha dos Annales, na medida em que se a considere como herdeira da História das mentalidades esboçada por Febvre e Bloch. Mentalidades presentes na obra de Febvre sobre Rabelais, por exemplo, ou na de Bloch sobre a crença no poder curativo do toque real, Les rois thaumaturges. Numa palavra, Phillipe Ariès foi um dos grandes expoentes da História das mentalidades francesa - e o foi avant la lettre -, além de ter sido o principal mentor da coleção História da vida privada analisada em meu artigo. Não vejo como não reconhecer nos historiadores franceses, para não falar nos intelectuais da civilisation do tempo das Luzes, os protagonistas da oficina que fez da vida privada um objeto da história. É de estranhar, portanto - e nisso contrario a opinião de Sheila de Castro Faria - que a vida privada não tenha figurado entre os novos objetos ou problemas do Faire de I'Histoire publicado em 1974. Afinal, Ariès havia publicado o seu História social da criança e da família em 1960, sem falar na massa crítica que sobre o assunto se havia acumulado na França desde o Setecentos.

Paradoxalmente, no entanto, foi na vizinha Alemanha, na terra da noção de Kultur, mais espiritual e conservadora do que racionalista e libertária, que surgiu a problematização pioneira e mais consistente das relações entre público e privado em perspectiva histórica. Fê-la o sociólogo Norbert Elias, a quem citei com o aval da maioria de meus debatedores, no seu magnífico $O$ processo civilizador. No primeiro volume da edição brasileira, Elias expôs o problema: a macro-história da oposição entre o mundo da civilisation e o da Kultur, núcleo da primeira parte da obra, e a micro-história (se me permitem) da lenta revolução dos comportamentos individuais ou a criação mesma da subjetividade, a partir dos manuais de civilidade da Época Moderna. No segundo volume, pôs-se a tecer os nexos entre construção da subjetividade e a formação do Estado, propondo enfim uma história da civilidade. Ariès é tributário das reflexões de Elias tanto como o é da tradição francesa. O mesmo se poderia dizer de Michel Foucault.

Mas foram os franceses que propuseram, não tenho dúvida, a vida privada como objeto da História. Fizeram-no, no entanto, de modo um tanto errático, por vezes desastrado, se tomarmos como exemplo a volumosa obra 
especificamente dedicada ao assunto nos anos 1980. Da imprecisão conceitual que perpassa o prefácio de Duby e a própria concepção e estrutura da obra, creio ter tratado suficientemente, contando com a aquiescência quase unânime dos comentaristas do texto. Nem por isso, vale lembrar, quis desqualificar a coleção ou os artigos nela incluídos, a maioria deles altamente renovadora. Neste sentido - e aqui abro um parêntesis especial para Lana Lage - não fui, nem poderia ser, implacável com Georges Duby, o grande medievalista que todos nós aprendemos a ádmirar, e cuja colaboração específica na obra é indiscutível. Não ousaria tanto. Mas não tive como evitar analisar e criticar os seus prefácios, dos quais esperava definições mais agudas do ponto de vista conceitual, e infelizmente só encontrei textos vagos e lacunosos. Mas que Duby não se resume àqueles prefácios sabemos todos muito bem, de sorte que o aparente desacordo "não há, nem é" (Vieira).

Dos prefácios e do conjunto da obra salta à vista a hesitação na definição conceitual do que pode ser a vida privada como objeto da História. Hesitação, antes de tudo, no enfrentamento da questão vida privada versus vida cotidiana. Percebe-se-a, conforme apontei no texto-base, no que diz Duby sobre a vida cotidiana, identificando-a à casa, aos usos e mores de antanho arrolados na deliciosa coleção da Hachette. Percebe-se-a em Jacques Le Goff, autor de um artigo que faz do cotidiano um conceito denso mas, como indica Petersen em seu comentário, só foi capaz de mecioná-lo onze vezes em $O$ maravilhoso e o cotidiano no Ocidente medieval, livro de 253 páginas.

A fluidez teórica que marca o conceito de vida privada e mesmo de vida cotidiana entre os historiadores franceses não deve ser, contudo, atribuída, a meu ver, ao predomínio de interesses de comercialização que fizeram da obra um autêntico best-seller. A mesma crítica foi feita, aliás, inúmeras vezes à própria História das mentalidades durante os anos 70 e 80 , isło é, a de que a renúncia à discussão teórica em favor da narrativa resultava, no fundo, de uma estratégia de marketing que visava o alargamento do público consumidor da bibliografia produzida academicamente.

No caso do presente debate, Falcon levantou esta possibilidade, embora de modo sutil, sugerindo que o interesse por esta temática, não obstante as dificuldades teóricas apontadas, derivaria do fato de "existir um público leitor curioso e indefinido, ávido por esse tipo de história...". E Sheila foi mais contundente, ao dizer que a História da vida privada organizada por Duby e Ariès "tornou-se mais um produto de mercado do que um conjunto de trabalhos para historiadores e estudiosos afins". Não vejo, sinceramente, maiores problemas em produzir história para mercado e, por meio disso, ampliar o público leitor e os meios de divulgação do trabalho acadêmico. Nem por isso a qualidade acadêmica da pesquisa fica necessariamente prejudicada. E, francamente, não penso que a produção historiográfica "exclusivamente acadêmica", se me permitem uma expressão como essa, encontra-se isenta de derrapagens teóricas ou que as hesitações teóricas dos estudiosos da vida privada derivem fundamentalmente dos propósitos de comercialização inerentes ao projeto.

Mas que os historiadores franceses realmente derrapam, salvo exceções como Ariès, no manejo do conceito de vida privada - o que se espelha 
na obra que escolhi analisar -, disso não tenho dúvida. E creio que todos os debatedores do meu texto-base concordaram com meus argumentos neste sentido, enriquecendo-os e adensando-os.

José de Souza Martins foi, sem dúvida, o crítico mais mordaz desta imprecisão, começando por estocar os historiadores franceses, depois o autor deste artigo e por pouco não pôs abaixo os historiadores em geral. Martins parece rejeitar, liminarmente, a vida privada e a vida cotidiana como objeto de uma história anterior à contemporânea: "são temas da atualidade", afirma Martins, "são temas da consciência social contemporânea e o são porque de algum modo são problemas para a sociedade". E nisso residiria um problema epistemológico grave no trabalho desses historiadores, na medida em que propõem um objeto "a partir de uma projeção retrospectiva do presente no passado".

Realmente, como afirma Martins, os historiadores são sempre homens (e mulheres) de seu próprio tempo - já o disse Lucien Febvre há décadas (sem as mulheres) -, sendo-nos totalmente impossível esła completa viagem no tempo que muitos ingenuamente acreditaram possivel, a exemplo de "algumas vidas cotidianas" publicadas pela Hachette. Problematizam sim o passado a partir do presente, mas se forem bons historiadores, procurarão trilhar os caminhos que permitam descobrir a alteridade no tempo. "O passado é um país estrangeiro", socorre-me uma vez mais Maria Lúcia Montes; e os historiadores que o visitam, levam consigo a bagagem cultural que costumam portar os viajantes. Nenhuma novidade há nisso, nem é qualquer especificidade dos que estudam vida privada ou vida cotidiana em tempos idos. Se neste percurso há um problema epistemológico grave, creio ser ele incorrigível, e houve mesmo quem dissesse que os historiadores são paradoxalmente anacrônicos por dever de ofício, condenados pelo cativeiro de seu próprio tempo, além de limitados pela tendenciosidade das fontes que utilizam.

Por outro lado, a crítica de Martins à adoção da vida privada ou do cotidiano como objetos universais da História - e no limite a-históricos -, parece ancorar-se em boa medida nas concepções de Henri Lefebvre acerca do assunto. Não me aventurarei a tratar de Lefebvre outra vez sem o devido conhecimento de causa - prometo -, mas valho-me de um breve comentário de Fernando Novais e Laura de Mello e Souza que talvez me ajude: "o que talvez se devesse observar é que Lefebvre, de certo modo, absolutiza as transformações, vinculando-as a uma gênese do capitalismo". Martins parece fazer o mesmo. Questão de opção teórica, claro está. Respeito-a, sem dúvida, mas tenho dificuldades para com ela concordar na totalidade.

É verdade, no entanto, que a vida privada pode ser melhor pensada, histórica e sociologicamente, como processo, e nisso concordei com a crítica de Martins aos historiadores da vida privada que a tomam de modo atemporal. 0 texto de Ph. Ariès, na coleção analisada, mostra muito bem as possibilidades mais fecundas desse enfoque, próximo ao de Norbert Elias, de sorte que não vi razão para maiores polêmicas quanto à minha posição neste ponto. Já o mesmo não ocorre com a noção de cotidiano, e nisso me apoiei, não na visão empiricista de boa parte dos livros da Hachette, mas em autores como Bloch e Braudel.

A noção de colidiano que procurei expor no artigo-base, considerando-a inclusive teoricamente mais densa do que a de vida privada, 
relaciona-se ao tempo braudeliano da longa duração, aos modos de sentir e pensar em sociedades historicamente consideradas, à cultura material, às relações entre o homem e o meio natural e às relações socialmente construídas. É uma noção de cotidiano - de "estruturas do cotidiano", para usar a expressão de Braudel - que inspirou e inspira numerosos trabalhos historiográficos. Noção diferente da que parece expor Lefebvre e advogar Martins em seu comentário, mas nem por isso ilegítima.

De todo modo, salvo por alguma escorregadela de que ninguém está livre, dizer que meu texto anterior "circunscreve a vida cotidiana aos usos e costumes e ao viver no interior da casa" não me parece realmente exato. Menos ainda o é dizer que a noção de cotidiano que utilizo é a do "senso comum, adicionalmente limitada pelo seu suposto desenrolar nos espaços mais típicos do privado..."

Sugeri, isto sim, o entrelaçamento das questões, pois a isto nos conduz a historiografia que sobre a matéria há, reconhecendo obviamente que as soluções desta equação dependerão das premissas teóricas do investigador.

Retornando, porém, à problemática da vida privada - pois é dela, afinal, que trata o presente dossiê -, verifico que a maioria dos debatedores tendeu a concordar com meu texto sobre a dificuldade de pensar-se a vida privada como conceito universal de preferência a pensá-la como processo.

Houve, porém, quem disso discordasse ou ao menos matizasse a afirmação com boas reflexões e provas. Foi o caso de Ciro Cardoso que, assumindo posição diametralmente oposta à de Martins, criticou os historiadores que desqualificam "a existência de algo até que apareçam disquisições formalizadas a respeito, eruditas e literárias", embora reconheça, obviamente, que cotidiano e vida privada assumiam formas profundamente diferentes das que viriam a conhecer no mundo contemporâneo. Ato contínuo, Cardoso resume a sua pesquisa sobre o arquivo privado de Hekanakht, no Egito Antigo, mostrando as possibilidades de uma história da vida privada avant la lettre somente inteligível em contraposição com a história do público. E, resumindo sua desconfiança em face dos que só admitem pensar um determinado objeto a partir de sua formalização conceitual, Ciro lembra uma frase de Shakespeare que dá muito o que pensar: "uma rosa teria o mesmo doce odor se se chamasse de qualquer outro jeito".

É também nesta linha, penso eu, que seguem Fernando Novais e Laura de Mello e Souza ao problematizarem a ocorrência de uma vida privada em contextos onde a esfera pública se apresenta frágil. Pensando o conceito de vida privada como conceito polar, oposto portanto ao público, Laura e Novais indicam as dificuldades de captar o que é o âmbito privado das sociedades, mormente as pré-capitalistas, nas quais os contrastes entre o público e o privado se esfumaçam. Mas nem por isso renunciaram a buscar os indícios da privacidade possível de ocorrer em sociedades anteriores ao século XIX: "recompor a pré-história da vida privada, apanhar o seu processo in fieri", como afirma Novais (1997), no prefácio do volume primeiro da História da vida privada no Brasil.

Foi esta problematização que os levou a construir a hipótese central do citado volume, intitulado "Cotidiano e vida privada na América Portuguesa" le 
vale notar a parceria dos conceitos no título): a hipótese de que, no Brasil Colônia, a fragilidade do poder público teria levado a uma hipertrofia do espaço privado sem que houvesse surgido vida privada em sentido estrito. Hipótese fecunda, e questão, em muitos aspectos, de inegável atualidade.

Esta última reflexão talvez responda à inquietação de José de Souza Martins quanto à dificuldade de aplicar os conceitos de vida privada e de cotidiano à sociedade brasileira do passado e mesmo do presente. Acrescentaria que reconhecer um caminho original, captar a especificidade histórica pode ser opção mais profícua do que refugiar-se em conceitos absolutos e supostamente indiscutiveis.

Assim sendo, concordaria plenamente com o ilustre sociológo quando afirma que, no período colonial, para dizer o mínimo, as casas vulneráveis, promíscuas e cheias de frestas "inviabilizavam a intimidade como a concebemos hoje e sobretudo os ritos próprios da vida privada". Cheguei mesmo a comentar o assunto, no mesmo sentido, aludindo a meu trabalho incluído na História da vida privada no Brasil. Escapa-me, portanto, o sentido do comentário de Martins quando me atribui um aparente desinteresse pelo "aparecimento das alcovas nas casas senhoriais das antigas fazendas". Mencionei o problema, como não poderia deixar de ser, no artigo-base do presente dossiê; explorei-o bastante em "Moralidades brasílicas", o capítulo da nova coleção; estudei o assunto já em Trópico dos pecados, livro de 1989. Este meu suposto desinteresse pelas alcovas nas casas coloniais e leitos, onde os havia, seria comparável, a meu ver, ao desinteresse de Martins pelo colonato ou pelo subúrbio, não fosse ele autor fundamental desses temas em nossa bibliografia.

Alcovas coloniais ou senhoriais à parte, se dermos um salto para o Rio de Janeiro da segunda metade do século XIX, nossa discussão se complexificaria e enriqueceria deveras. Refiro-me às considerações de Fernanda Bicalho sobre sua pesquisa acerca da imprensa feminina na capital do Império, o nosso. Jornais, vale dizer, escritos por mulheres e a elas dirigidos como público-alvo em plena sociedade "patriarcal e escravista". Fernanda nos mostra, rastreando a manifestação do individualismo numa sociedade não-burguesa (ou não totalmente) que, não obstante o espaço privado fosse locus privilegiado para a construção de uma subjetividade e identidade femininas, a imprensa, veículo por excelência do espaço público, foi o instrumento eleito para a expressão desta identidade, abrindo às mulheres uma brecha para ultrapassarem a casa como espaço de afirmação. E daí sugere, tratando de sociedade onde o arcaico e o burguês conviviam (como talvez convivam) de forma tensa e paradoxal, que público e privado possam ser pensados como esferas interpenetráveis, das sociedades, e não necessariamente opostas, em perspectiva histórica. É um exemplo de sociedade "periférica" e escravista, embora parcialmente aburguesada na época. Mas é também exemplo do caráter necessariamente polar da vida privada como conceito.

Aproximamo-nos da conclusão, mas não poderia encerrar este texto sem esclarecer questão levantada no final do texto-base e discutida por diversos debatedores do artigo. Refiro-me às relações que estabeleci entre a História da vida privada à moda francesa e a velha História das mentalidades, bem como às críticas de Ciro Cardoso a essas correntes, as quais retomei como mote para 
discussão. A vários debatedores minha posição sobre o assunto pareceu inconclusa e alguns deles, em face do espaço vazio deixado pelo texto, dirigiram sua crítica a Cardoso e a mim, questionando se afinal estou de acordo ou não com Ciro acerca da inserção da História da vida privada no paradigma pósmoderno de que fala o autor de História de paradigmas rivais.

Falcon pergunta sem rodeios qual a minha opinião, na verdade, acerca da vinculação entre mentalidades, vida privada e o paradigma hermenêutico da pós-modernidade. Laura e Novais defendem o citado paradigma apontando, com razão, suas potencialidades teóricas e heurísticas, considerando que levantei a posição de Ciro, antes para estimular o debate, do que para externar minhas próprias convicções. Celeste Zenha se preocupa menos com minha posição, mas nem por isso deixa de fazer longas considerações em defesa da chamada Nova História, ao menos de algumas de suas vertentes. Lana Lage, enfim, para encurtar este breve balanço, provoca-me no limite, sugerindo que, se estou a defender a posição de Cardoso, não tenho como defender a história que eu mesmo pratico.

Estou absolutamente convencido, antes de tudo, de que a questão proposta possui a relevância que julgava ter. E admito, também, que não fui suficientemente claro na exposição de minhas convicções a respeito, de sorte que tentarei uma segunda vez.

Assim sendo, cabe-me, em primeiro lugar, contextualizar bibliograficamente as posições de Cardoso sobre o assunto, não somente porque a matéria é pertinente, mas porque percebi que a menção genérica às suas opiniões fê-lo, de súbito, centro de um tiroteio de idéias ao qual não compareceu de molu proprio, senão por via de minhas considerações, neste ponto superficiais.

Esclareço, portanto, que o texto de Ciro por mim citado foi o recentíssimo "História e paradigmas rivais", a introdução de Domínios da Hlstória que com ele organizei, publicado neste ano de 1997, e não "Uma Nova História?", texto incluso nos Ensaios racionalistas de 1988. À diferença de quase 10 anos entre os dois textos corresponde, seguramente, se não uma mudança substantiva de juízo, considerável relativização e fundamentação das opiniões, para não falar das intenções dos textos: o primeiro, texto de polêmica; o segundo, texto de mapeamento das grandes correntes da história contemporânea.

Além disso, se no texto de 1988 Cardoso revelava evidente má vontade com a historiografia produzida no pós-68, incluindo os temas por ela freqüentados no âmbito da história cultural, no ensaio de 1997 explicita a diferença teórica entre os paradigmas e sugere que o ideal é a compatibilização entre as duas escalas de observação. Não é ocioso dizer que desta reflexão do autor resultou, em boa parte, nossa idéia de organizar os Domínios da História recém-publicado.

No meu entender, o que substantivamente não mudou nas opiniões de Cardoso sobre algumas vertentes da Nova História é o juízo sobre a recusa, por parte de algumas delas, em explicitar e adensar as referências teóricas de suas investigações, característica que o autor viu mesmo nos próprios fundadores dos Annales, mas sobretudo na geração pós-braudeliana. 
Se estou de acordo com isto? Sim, sem dúvida, no que toca a certos estudos da velha História das mentalidades, e mesmo a certas formulações de um Jacques Le Goff, por exemplo, que no célebre artigo de 1974, "As mentalidades: uma história ambígua", sugeriu ser o "inconsciente coletivo" um dos territórios privilegiados deste campo de pesquisa. Carlo Ginzburg (1991) já justificou plenamente, por sinal, no seu Prefácio de $O$ queijo e os vermes, o por quê de ter abandonado o conceito de mentalidades em favor da noção de cultura popular e da problemática da circularidade entre os niveis culturais. Justificou-o frisando a imprecisão do conceito de mentalidade em termos da estratificação e do conflito social, com o que estou de pleno acordo.

Esta incúria, por assim dizer, no domínio da teoria, foi o que procurei indicar nas minhas análises, inclusive quantitativas, da coleção francesa dedicada à história da vida privada. Imprecisões e negligências que não se repetem, felizmente, no volume primeiro da História da vida privada no Brasil, organizado por Laura e Novais. Repito, portanto, o que enunciei no artigo-base e no meu próprio capítulo de Domínios da HIstória: a história da vida privada, concebida à moda francesa, exemplifica e dá razão plenamente ao que Cardoso diz sobre algumas correntes da Nova História, o que, noutros termos, disseram Vovelle, na própria França, e Carlo Ginzburg, na ltália.

Neste sentido, vejo Uma História íntima da humanidade, citado com grande entusiasmo por Celeste Zenha, um exemplo-mor do que Ciro chamaria de pulsões irracionalistas dos historiadores pós-modernos. Afinal, são "os fantasmas familiares" o objeto preferencial de Zeldin, para quem a história dos indivíduos tem a ver com heranças geracionais, às quais não faltam, como fundamentação, argumentos biologizantes e psicologizantes. Análogo (mas não idêntico, Celeste) ao tema da intimidade geracional, seria a dita ego-História, também um fenômeno francês, que, não obstante seu interesse, faz dos próprios historiadores objeto da história. Melhor é, penso eu, falar em historiografia, pois ego-História é algo que, no limite, simplesmente dilui e confunde sujeito e objeto, procedimento deveras comprometedor para qualquer forma de conhecimento. $O$ que diria Sennett de uma história da intimidade, ele que, com acuidade, denunciou a tirania dela no mundo atual? Creio que minha posição está, agora, um pouco mais clara a este respeito.

A discordância que tenho em relação a Ciro é dupla, uma otimista para a chamada Nova História, a outra nem tanto. A primeira é que penso ser a História Cultural, numa versão como a de Ginzburg ou mesmo Thompson, um grande avanço em relação à história das mentalidades um tanto vaga dos franceses, da qual sua história da vida privada é herdeira. A discordância pessimista, se é que disto se trata, é que creio ser extremamente difícil, em função da diferença entre as escalas de observação, conjugar sistematicamente o nível micro-histórico e o macro-histórico de investigação, e nisto relembro Revel e espero responder a uma interpelação pertinente de Falcon.

A citação de Revel assim se justifica, ainda que Ginzburg, por exemplo, suponha resolver o problema das classes renunciando ao conceito panclassista de mentalidade. Afinal, que garantia há de que a diferença/oposição entre classes sociais no plano cultural encontra correspondência exata no campo do conflito social? Esta é uma boa discussão - 
só de mencioná-la imagino mais uns três parágrafos - a que prudentemente renunciarei, pois o texto final vai mais longe do que o desejável.

E já que menciono Falcon, verdadeiramente incansável na arte de questionar, creio haver muito de historicismo ou neo-historicismo nas tendências historiográficas atuais, quer no Brasil, quer alhures. Mas devo dizer que isto pode ser motivo de grande satisfação para os historiadores de hoje, pois o historicismo que sem dúvida vejo renascer (em alguns países jamais feneceu) tem a ver com o apreço pela pesquisa, o gosto pela descoberta dos arquivos, o apego pelo diálogo solitário com os documentos. Diálogo solitário, vero, mas com documentos em série cotejados com outros documentos. Documentos que não falam por si - e aqui nos afastamos de uma "escola metódica" por exemplo, embora ela nos ensine muito sobre a crítica inestimável das fontes. Repondi aquém do que Falcon desejaria, estou certo, mas respondo o essencial: pesquisa e teoria devem, a meu ver, andar juntas.

Vida privada, nosso ponto de partida, deve ser também o termo deste comentário final. Celeste Zenha diz bem quando desconfia da vida privada como conceito universal (também desconfiọ dele ou delal, sugerindo que a problemática a ser discutida é a tensão entre o poder institucional e o particular, esta sim abrangente em termos de temporalidade. Fernanda Bicalho sugere encarar público e privado como esferas interpenetráveis, não necessariamente confusas e opostas, - e não só no passado pré-burguês, mas igualmente na era do capitalismo ou em tempos e sociedades híbridas. Laura de Mello e Souza e Fernando Novais não têm dúvida em identificar a vida privada como conceito polar, e disso me convenceram de vez: a vida privada só faz sentido, como problemática de investigação histórica, se contraposta ao domínio do público tensões, oposições, hipertrofias paradoxais de uma ou de outro.

Talvez nisso resida o essencial ou a idéia mais resistente deste debate: a licitude de se investigar a vida privada em perspectiva histórica, tomando-se-a não como universo fechado a desafiar a hermenêutica do sujeito, mas como conceito polar e relacional. E, neste sentido, conforme o tempo e a sociedade, privado e público poderão estabelecer aproximações e distanciamentos muito diferenciados no tempo e no espaço. Dito à moda de Shakespeare, aqui lembrado por Ciro, a rosa é sempre rosa, mas sentir ou não o seu perfume é questão de chance e de circunstâncias. 


\section{BIBLIOGRAFIA GERAL}

ARIÈS, Philippe. História Social da criança e da familia. Rio de Janeiro: Zahar, 1981.

ARIÈS, Philippe. Um bistoriador diletante. Rio de Janeiro: Bertrand, 1994.

ARIÈS, Philippe, DUBY, Georges (Org.) História da vida privada. São Paulo: Companhia das Letras, 1990-1992.5 v.

ARIÈS, Philippe. Para uma história da vida privada. In: ARIÈS, Philippe, CHARTIER, Roger (Org.) História da vida privada: Da Renascença ao século das luzes. São Paulo: Companhia das Letras, 1992. v.3, p.7-20. (ed. ital. 1988).

BALANDIER, Georges. Modernidad y poder: el desvío antropológico. Madrid: Júcar, 1988.

BARROS, Maria Paes de. No tempo de dantes. São Paulo: Brasiliense, 1946.

BICALHO, Maria Fernanda B. O bello sexo: imprensa e identidade feminina no Rio de Janeiro em fins do século XIX e início do século XX. Dissertação (Mestrado) - PPGAS, Museu Nacional/Universidade Federal do Rio de Janeiro, 1988.

BLOCH, Marc L. B. A sociedade feudal. Lisboa: Edições 70, 1982.

BOURDIEU, Pierre. A economia das trocas simbólicas. São Paulo: Perspectiva, 1992.

BRAUDEL, Fernand. Civilisation matërielle, économie et capitalisme. Paris: Armand Colin, 1967.

BURGUIÈRE, A. Antropologia Histórica. In: Dicionário das ciências bistóricas. Rio de Janeiro: Imago, 1993.

CANGUILHEM, G. O normal e o patológico. Rio de Janeiro: Forense Universitária, 1982.

CARDOSO, Ciro Flamarion. Uma Nova História? In: Ensaios racionalistas. Rio de Janeiro: Campus, 1988. p.93-117.

CARDOSO, Ciro Flamarion. História e paradigmas rivais. In: CARDOSO, Ciro Flamarion, VAINFAS, Ronaldo (Org.) Os domínios da bistória: ensaios de teoria e metodologia. Rio de Janeiro: Campus, 1997. p.1-27.

CARDOSO, Ciro Flamarion. Hekanakht: pujança passageira do privado no Egito antigo. Tese (para concurso de professor titular de História Antiga) - Niterói, Universidade Federal Fluminense, 1993.

CARVER, Martin (Org.) The age of Sutton Hoo: the seventh century in Northern Europe. Woodbridge/Rochester: The Boydell Press, 1992. 
CHARTIER, Roger. Figuras da modernidade. In: ARIÈS, Philippe, DUBY, Georges (Org.) História da vida privada. São Paulo: Companhia das Letras, 1990 - 1992.

CLASTRES, Pierre. A sociedade contra o Estado. Rio de Janeiro: Francisco Alves, 1988.

DARNTON, Robert. O beijo de Lamourette: mídia, cultura e revolução. São Paulo: Companhia das Letras, 1990.

DEL PRIORE, Mary. História do cotidiano e vida privada. In: CARDOSO, Ciro Flamarion, VAINFAS, Ronaldo (Org.) Os dominios da bistória: ensaios de teoria e metodologia. Rio de Janeiro: Campus, 1997.

DUBY, Georges. O historiador hoje. In: LE GOFF, Jacques. História e Nova História. Lisboa: Teorema, 1986.

DUBY, Georges. A história, um divertimento, um meio de evasão, um meio de formação. In: LE GOFF, Jacques. A Nova História. Lisboa: Edições 70, 1984.

DUBY, Georges. Prefácio. In: VEYNE, Paul (Org.) História da vida privada: Do Império Romano ao ano mil. São Paulo: Companhia das Letras, 1992.

DUBY, Georges. Poder privado, poder público. In:ARIĖS, Philippe, DUBY, Georges (Org.) História da vida privada:Da Europa Feudal à Renascença. São Paulo: Companhia das Letras, 1991. v.2.

DUMONT, Louis. O individualismo, uma perspectiva antropológica da ideologia moderna. Rio de Janeiro: Rocco, 1985.

ELIAS, Norbert. O processo civilizador: uma história dos costumes. Rio de Janeiro: Jorge Zahar, 1990.

FALCÃO, Luiz Felipe. O poder da teoria. Porto Alegre: Programa de pós-graduação em História da Universidade Federal do Rio Grande do Sul, 1990. (datilografado).

FALCON, Francisco C. História e poder. In: CARDOSO, Ciro Flamarion, VAINFAS, Ronaldo (Org.) Os dominios da bistória: ensaios de teoria e metodologia. Rio de Janeiro: Campus, 1997. p. $61-90$

FLANDRIN, Jean-Louis. Le sexe et l'Occident. Paris: Seuil, 1981,

FLANDRIN, Jean-Louis. Familles: parenté, maison, sexualité dans l'ancienne société. Paris: Seuil, 1984.

FOUCAULT, Michel. As palauras e as coisas: uma arqueologia das ciências humanas. Tradução por Salma Tannus Muchail e revisão por Roberto Cortes de Lacerda. São Paulo: Martins Fontes, 1987. 
FOUCAULT, Michel. História da sexualidade III (O cuidado de si). Rio de Janeiro: Graal, 1985.

FRANKLIN, Benjamin. Autobiografia. Tradução por Aydano Arruda. São Paulo: Ibrasa, 1963.

GEERTZ, Clifford. A interpretação das culturas. Rio de Janeiro: Zahar, 1978.

GINZBURG, Carlo. História noturna: decifrando o sabá. São Paulo: Companhia das Letras, 1991.

GINZBURG, Carlo. O queijo e os vermes: o cotidiano e as idéias de um moleiro perseguido pela Inquisição. São Paulo: Companhia das Letras, 1991.

GODINHO, V., LABROUSSE, E. et al. A História Social: problemas, fontes e métodos. Lisboa: Cosmos, 1973. (Colóquio da Escola Normal Superior de Saint-Cloud, 15-16 maio 1965).

GOFFMAN, Erving. La presentación de la persona en la vida cotidiana. Tradução por Hildegarde B. Torres Perrén e Flora Setaro. Buenos Aires: Amorrortu, 1971.

GUATTARI , F., ROLNIK, Suely. Micropolitica: cartografias do desejo. Petrópolis: Vozes, 1986.

GUREVICH, Aron. Medieval popular culture: problems of belief and perception. Tradução por J. M. Bak e P. A. Hollings-Worth. Cambridge: Cambridge University Press/Paris: Éditions de la Maison des sciences de l'homme, 1988.

HABERMAS, Jürgen. Mudança estrutural da esfera püblica: investigações quanto a uma categoria da sociedade burguesa. Rio de Janeiro: Tempo Brasileiro, 1984.

HEDEAGER, Lotte. Iron-Age societies. Tradução por J. Hines. Oxford: Blackwell, 1992.

HUIZINGA, Johan. O declinio da Idade Média. Tradução por Augusto Abelaira. Lisboa: Verbo/São Paulo: Edusp, 1978. (1.ed. 1919)

JAMES, T. G. H. The Hekanakhte papers and other early Middle Kingdom documents. New York: The Metropolitan Museum of Art, 1962.

KEHL, Maria Rita. A minima diferença: masculino e feminino na cultura. Rio de Janeiro: Imago, 1997.

KLAEBER, F. (edição, introdução, bibliografia, notas, glossário e apêndices de). Beowulf and the fight at Finnsburg. 3.ed. Lexington (Mass.): D.C. Heath, 1950.

KRISTIANSEN, Kristian. Chiefdoms, states, and systems of social evolution. In: EARLE, Timothy (Org.) Chiefdoms: power, economy, and ideology. Cambridge: Cambridge University Press, 1991.

LE GOFF, Jacques. Documento/monumento. In: Enciclopédia Einaudi. Lisboa: Imprensa Nacional, 1984. p.95-106. n.1 (Memória-História). 
LE GOFF, Jacques. História do quotidiano. In: DUBY, Georges et alii. História e Nova História. Lisboa: Teorema, 1986. p.73-82.

LE GOFF, Jacques. As mentalidades: uma história ambígua. In: LE GOFF, Jacques, NORA, Pierre (Org.) História: novos objetos. Rio de Janeiro: Francisco Alves, 1976. p.68-83.

LE GOFF, Jacques, NORA, Pierre (Crg.) História: novos objetos; novos problemas; novas abordagens). Rio de Janeiro: Francisco Alves, 1976. 3v.

LEFEBVRE, Henri. A vida cotidiana no mundo moderno. São Paulo: Ática, 1991.

LEFEBVRE, Henri. La notion de totalité dans les sciences sociales. Cabiers internationaux de Sociologie, Paris, Presses Universitaires de France, v.18, jan./juin 1955.

LEFEBVRE, Henri. La vida cotidiana en el mundo moderno. Tradução por Alberto Escudero. Madrid: Alianza Editorial, 1972.

LEFEBVRE, Henri. La survie du capitalisme: la re-production des rapports de production. Paris: Anthropos, 1973.

LEFEBVRE, Henri. La présence et l'absence: contribution à la théorie des représentations. Paris: Casterman, 1980.

LEFEBVRE, Henri. Critique de la vie quotidienne (III. De la modernité au modernisme: pour une métaphilosophie du quotidien). Paris: L'Arche, 1981.

LEGENDRE, Pierre. O amor do censor: ensaio sobre a ordem dogmática. Tradução por Potiguara Mendes Silveira Junior. Rio de Janeiro: Forense Universitária/Colégio Freudiano, 1983.

LEME, Luiz Gonzaga da Silva. Genealogia paulistana. São Paulo: Duprat \& Comp., 1903-5. 9v.

LEME, Pedro Taques de Almeida Paes. Nobiliarquia paulistana histórica e genealógica. Belo Horizonte: Itatiaia/São Paulo: Edusp, 1980. 3t. (1.ed.: 1879).

LÉVI-STRAUSS, Claude. La pensée sauvage. Paris: Plon, 1962.

LÉVI-STRAUSS, Claude. Antropologia estrutural dois. Rio de Janeiro: Tempo Brasileiro, 1978.

LÉVI-STRAUSS, Claude. Mito e significado. Lisboa: Edições 70, 1989.

LÉVI-STRAUSS, Claude. O cru e o cozido: mitológicas. São Paulo: Brasiliense, 1991.

LIMA, Lana Lage da Gama. A confissão pelo avesso: o crime de solicitação no Brasil colonial. Tese (Doutorado) - Universidade de São Paulo, 1990.

MAFFESOLI, Michel. O conbecimento comum. Tradução por Aluizio Ramos Trinta. São Paulo: Brasiliense, 1988 
MARQUES, Manuel Eufrásio de Azevedo. Apontamentos bistóricos, geográficos, biográficos, estatísticos e noticiosos da Província de São Paulo. São Paulo: Livraria Martins Editôra, 1952. t.2 (1.ed.: 1879).

MARTINS, José de Souza. Subürbio: vida cotidiana e história no subúrbio da cidade de São Paulo (São Caetano, do fim do Império ao fim da República Velha). São Paulo: Hucitec, 1992.

MARTINS, José de Souza. O poder do atraso: ensaios de sociologia da história lenta. São Paulo: Hucitec, 1994.

MARTINS, José de Souza (Org.) Henri Lefebure e o retorno à dialética. São Paulo: Hucitec, 1996.

MARTINS, José de Souza (Org.) (Des)figuraçōes: a vida cotidiana no imaginário onírico da metrópole. São Paulo: Hucitec, 1996.

NAVARRO, Martim de Azpilcueta. Capitulo veynte y ocho de las adiciones del Manual de confesores.

NOGUEIRA, Paulo de Almeida. Minba vida (diário de 1893 a 1951). São Paulo: Revista dos Tribunais, 1955.

NOVAIS, Fernando. Prefácio. In: Souza. Laura de Mello e, NOVAIS, Fernando (Coord.) História da vida privada no Brasil: Cotidiano e vida privada na América Portuguesa. São Paulo: Companhia das Letras: 1997. v1. p. 7-11.

PETERSEN, Silvia Regina Ferraz. Dilemas e desafios da historiografia brasileira: a temática da vida cotidiana. História e Perspectivas, Uberlândia, v.6, p.24-44. jan./jun. 1992.

PETERSEN, Silvia Regina Ferraz. Michel Maffesoli: um teórico da vida cotidiana. Biblos, Rio Grande, FURG, v.5, p.41-55, 1993.

PETERSEN, Silvia Regina Ferraz. A renovação da historiografia e a temática da vida cotidiana: desfazendo alguns equívocos. In: MAUCH, Claudia (Org.) Porto Alegre na virada do século XIX: cultura e sociedade. Porto Alegre: Editora da Universidade Federal do Rio Grande do SUl/ULBRA/UNISINOS, 1994. p.112-25.

PETERSEN, Silvia Regina Ferraz. O cotidiano como objeto teórico ou o impasse entre ciência e senso comum no conhecimento da vida cotidiana. In: MESQUITA, Zilá, BRANDÃO, Carlos Rodrigues. (Org.) Territórios do cotidiano: uma introdução a novos olhares e experiências. Porto Alegre: Editora da Universidade Federal do Rio Grande do Sul/EDUNISC, 1995. p.30-9.

PROST, Antoine. Fronteiras e espaços do privado. In: VINCENT, Gérard, PROST, Antoine (Org.) História da vida privada: Da Primeira Guerra aos nossos dias. São Paulo: Companhia das Letras, 1992. v.5.

RANDSBORG, Klavs. The town, the power, and the land: Denmark and Europe during the first millenium AD. In: CHAMPION, T.C. (Org.) Centre and periphery. London/New York: Routledge, 1989. 
REVEL, J. Micro-analyse et construction du social. In: REVEL, J. (Org.) Jeux d'échelles: la micro-analyse à l'expérience. Paris: Gallimard/Seuil, 1996.

SAHLINS, Marshall. Islas de bistoria: la muerte del capitán Cook, metáfora, antropología e historia. Barcelona: Gedisa, 1988.

SANTOS, Boaventura de Souza. Introdução a uma ciência pós-moderna. Rio de Janeiro: Graal, 1989.

SARTRE, Jean-Paul. Crítica de la razón dialéctica. Tradução por Manuel Lamana. Buenos Aires: Losada, 1970. Libro I.

SCHUTZ, Alfred. El problema de la realidad social. Tradução por Néstor Míguez. Buenos Aires: Amorrortu, 1974.

SENNETT, R. O declinio do bomem público. São Paulo: Companhia das Letras, 1989.

SIMMEL, Georg. On individuality and social forms. Chicago: The University of Chicago Press, 1971.

SIMMEL, Georg. Cultura feminina. Lisboa: Galeria Panorama, [19-?]. (Posteriormente reeditado em Pbilosophie de la modernité: la femme, la ville, l'individualisme. Paris: Payot, 1989. p. 113-59).

SOUZA, Laura de Mello e, NOVAIS, Fernando A. (Coord.) História da vida privada no Brasil: cotidiano e vida privada na América Portuguesa. São Paulo: Companhia das Letras, 1997. v.1.

THÉBERT, Yvon. Vida privada e arquitetura na África romana. In: VEYNE, Paul (Org.) História da vida privada: Do Império Romano ao ano mil. Tradução por Hildgard Feist. São Paulo: Companhia das Letras, 1990. v.1.

TRIGGER, Bruce. Egyptology and Anthropology. In: WEEKS, Kent (Org.) Egyptology and the social sciences. Cairo: The American University in Cairo Press, 1979.

VAINFAS, Ronaldo. Ideologia E escravidão: os letrados e a sociedade escravista no Brasil colonial. Petrópolis: Vozes, 1986. (Coleção História Brasileira, 8).

VAINFAS, Ronaldo. Trópico dos pecados. Rio de Janeiro: Campus, 1989.

VAINFAS, Ronaldo. A beresia dos indios: catolicismo e rebeldia no Brasil colonial. São Paulo: Companhia das Letras, 1995.

VAINFAS, Ronaldo. História das mentalidades e História Cultural. In: CARDOSO, Ciro Flamarion, VAINFAS, Ronaldo (Org.) Os dominios da bistória: ensaios de teoria e metodologia. Rio de Janeiro: Campus, 1997a. 
VAINFAS, Ronaldo. Moralidades brasílicas... In: SOUZA, Laura de Mello e, NOVAIS, Fernando A. (Coord.) História da vida privada no Brasil: cotidiano e vida privada na América Portuguesa. São Paulo: Companhia das Letras, 1997b. v.1.

VEYNE, Paul. O Inventário das diferenças: História e Sociologia. São Paulo: Brasiliense, 1983. (1.ed. 1976).

WEBER, Max. The protestant etbic and the spirit of capitalism. Transl. by Talcott Parsons. New York: Charles Scribner's Sons, 1958.

WEBER, Max. Economia y sociedad: esbozo de sociología comprensiva. Tradução por José Medina Echavarria et alii. Mexico/Buenos Aires: Fondo de Cultura Económica, 1964. t.1.

WHITELOCK, Dorothy. The audience of Beowulf. Oxford: Clarendon, 1951.

WILSON, Peter J. The domestication of the buman species. New Haven/London: Yale University Press, 1988.

WOLFROMM, J-D. Quarenta anos de vida quotidiana. In: LE GOFF, Jacques et al. A Nova História. Lisboa: Edições 70, 1984. p.65-8.

ZELDIN, Theodore. Uma bistória intima da bumanidade. Rio de Janeiro: Record, 1996. 